\title{
Fabrication of Porous Aluminum with Controllable Open-Pore Fraction
}

\begin{abstract}
PENG YU, M. YAN, G.B. SCHAFFER, and MA QIAN
Aluminum with an open-pore structure was fabricated through nitridation of an AA6061-2 pct Mg-1 pct Sn powder mixture, where interconnected permeable AlN shells developed on each AA6061 particle and imparted strength to the assembly. The resulting intershell spaces form an open-pore structure. When such an open-pore structure is heated above the liquidus of the core, an open-closed pore transformation occurs, where the molten core in each shell spontaneously migrates to fill the open pores outside, leaving a closed pore inside each shell. Based on this finding, porous AA6061 with different open-pore fractions was fabricated by heating open-pore structures of AA6061 into the semisolid region, where the liquid fraction changes with temperature. The mechanism for the open-closed pore transformation is identified through detailed microstructural and thermodynamic analyses. Criteria for the open-closed pore transformation are specified. Additionally, net shape fabrication of porous aluminum with controlled pore features is realized using the novel concept.
\end{abstract}

DOI: $10.1007 / \mathrm{s} 11661-011-0675-2$

(C) The Minerals, Metals \& Materials Society and ASM International 2011

\section{INTRODUCTION}

HiGHLY porous materials have found wide application in various industries ${ }^{[1-3]}$ due to their interesting combinations of physical and mechanical properties, ${ }^{[4,5]}$ such as high stiffness in conjunction with very low specific weight ${ }^{[6]}$ or high gas permeability combined with high thermal conductivity. ${ }^{[7]}$ Based on the connectivity of pores, porous metals are typically divided into two broad categories: ${ }^{[8]}$ (1) open-pore metals, known as metal sponges, in which pores are interconnected to form a percolating structure permitting the passage of gases and liquids; and (2) close-pore metals, known as metal foams, in which pores are isolated from each other by cell walls.

Open-pore metals are conventionally fabricated through two processing routes. One is through a replication process, which begins by creating a porous preform whose open pores are filled with the foam material. Then the preform is removed by leaching or shaking, leaving an interconnected porous network within the foam material. ${ }^{[9]}$ The other is through sintering of loose metal powder or fibers. The closepore metals are overwhelmingly fabricated by foaming of liquid metal. First, a molten metal is oxidized or mixed with ceramics to increase its viscosity. Second, gases are introduced through blowing agents or external gas sources to form liquid metal foams. The

PENG YU, Research Fellow, M. YAN, Australian Postdoc Research Fellow, G.B. SCHAFFER, Professor, and MA QIAN, Associate Professor, are with the School of Mechanical and Mining Engineering, ARC Centre of Excellence for Design in Light Metals, The University of Queensland, QLD 4072, Australia. Contact e-mail: yp1975@gmail.com

Manuscript submitted November 14, 2010.

Article published online March 29, 2011 subsequent cooling produces a close-pore metal through solidification of the liquid. ${ }^{[10]}$ While close-pore metals have found application as load bearing, structural components, and energy absorbers ${ }^{[11,12]}$ functions such as filtration, separation, catalyst support, bone replacement, and heat/mass exchange require desired openpore structures. ${ }^{[13,14]}$

Encouraging progress has been made in the control of the size, shape, and uniformity of the pores in porous materials over the years. ${ }^{[15-17]}$ However, it remains challenging to control the open-pore fraction in cellular metals. Furthermore, once a metal foam is produced, it is no longer possible to alter the pore morphology and the relative proportion of the open or closed pores. This work presents a novel method, which allows for an open-closed pore transformation in cellular aluminum, facilitating the control of pore structure in cellular aluminum materials.

\section{EXPERIMENT}

The feed stock was prepared by mixing prealloyed AA6061 powder with 2 pet $\mathrm{Mg}$ and 1 pet Sn (all in wt pct). The aluminum powder was argon atomized, with a particle size range 15 to $75 \mu \mathrm{m}$. Both the $\mathrm{Mg}$ powder and the Sn powder are $<45 \mu \mathrm{m}$. A mix of $400 \mathrm{~g}$ was poured into a steel crucible (dimensions: $200 \mathrm{~mm} \times$ $200 \mathrm{~mm} \times 60 \mathrm{~mm}$ ) and covered with a loose fitting lid. The crucible was placed in an electrical resistance furnace, which was evacuated with a rotary pump to $10 \mathrm{~Pa}$ before being filled with flowing nitrogen $(5 \mathrm{~L} / \mathrm{min})$. The furnace was subsequently heated to $833 \mathrm{~K}\left(560{ }^{\circ} \mathrm{C}\right)$ and held at temperature for 12 hours during which period nitridation occurred, leading to the formation of an AlN skeleton. ${ }^{[18-21]}$ The mix was thus transformed into an open-pore aluminum. After cooling to room 
temperature in the furnace, the sample was sectioned into equal parts. They were then treated at $893 \mathrm{~K}$, $913 \mathrm{~K}, 923 \mathrm{~K}$, and $973 \mathrm{~K}\left(620^{\circ} \mathrm{C}, 640{ }^{\circ} \mathrm{C}, 650{ }^{\circ} \mathrm{C}\right.$, and $700{ }^{\circ} \mathrm{C}$ ) for 2 hours in a vacuum of $10 \mathrm{~Pa}$ to transform the pore structure.

The bulk density $(\rho)$ and open porosity $\left(P_{o}\right)$ of each sample were determined using the Archimedes method through Eqs. [1] and [2]:

$$
\begin{gathered}
\rho=\frac{W_{1}}{W_{2}-W_{1}} \cdot \rho_{2} \\
P_{o}=\frac{W_{2}-W_{1}}{W_{2}-W_{3}} \cdot \frac{\rho_{2}}{\rho_{1}}
\end{gathered}
$$

First, the weight of the sample $\left(W_{1}\right)$ was measured in air. Then, the sample was immersed in oil (Javac 16 [JAVAC, Knoxfield, VIC, Australia], $\rho_{1}=0.86 \mathrm{~g} \mathrm{~cm}^{-3}$ at $293 \mathrm{~K}$ $\left(20{ }^{\circ} \mathrm{C}\right)$ ) and pumped to $10 \mathrm{~Pa}$ for 10 minutes to fill the open pores. After cleaning, it was weighed again in air $\left(W_{2}\right)$. Finally, it was soaked and weighed $\left(W_{3}\right)$ in distilled water $\left(\rho_{2}=0.998 \mathrm{~g} \mathrm{~cm}^{-3}\right.$ at $\left.293 \mathrm{~K}\left(20{ }^{\circ} \mathrm{C}\right)\right)$.

To calculate the total porosity, a portion of an untreated sample was hot extruded at $673 \mathrm{~K}\left(400^{\circ} \mathrm{C}\right)$ at a ratio of 9:1. The extruded sample was confirmed to be pore free by optical microscopy. Its density was determined to be $\rho_{0}=2.80 \mathrm{~g} \mathrm{~cm}^{-3}$ using the Archimedes method. The relative density $R D$ and total porosity $P$ were calculated by

$$
P=1-R D=1-\frac{\rho}{\rho_{0}}
$$

The open-pore fraction $f_{o}$ is defined as the ratio of the open porosity $P_{o}$ to the total porosity $P$

$$
f_{o}=\frac{P_{o}}{P}
$$

The microstructure was examined using a Polyvar optical microscope, a PHILIPS* XL30 scanning electron

*PHILIPS is a trademark of FEI Company, Hillsboro, OR.

microscope (SEM), and a Tecnai F20 transmission electron microscope (TEM). THERMO-CALC software TCW5 and Database Aluminium v6 were used to calculate the phase constituents (Thermo-Calc Software, Stockholm, Sweden). Cylindrical specimens $(5 \mathrm{~mm} \times$ $10 \mathrm{~mm}$ o.d.) were machined out of untreated and treated samples. Compression tests were conducted at a strain rate of $10^{-2} \mathrm{~min}^{-1}$.

A demonstration part was fabricated to show the potential of the process for the fabrication of net shapes. AA6061-2 pet Mg-1 pet Sn-3 pct Nylon powder was used as a feed stock. A green part was built using a 3D System SinterStation Plus selective laser sintering machine (3D Systems Corporation, Rock Hill, SC). It was then subjected to 12 hours nitridation at $833 \mathrm{~K}\left(560{ }^{\circ} \mathrm{C}\right)$ to
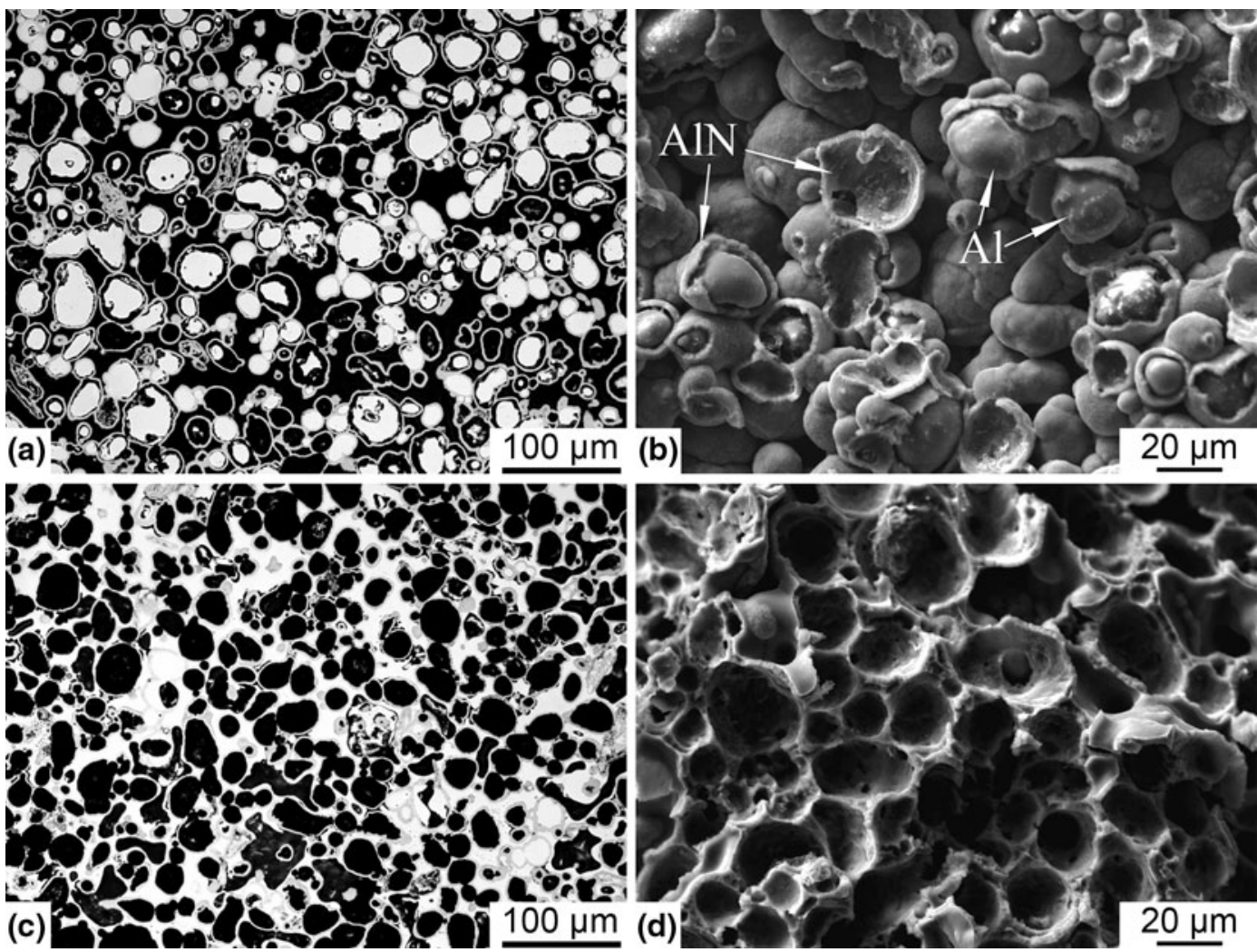

Fig. 1-(a) Optical micrograph of an as-nitrided sample. (b) SEM fractograph of (a). (c) Optical micrograph of (a) after the transformation treatment at $973 \mathrm{~K}\left(700^{\circ} \mathrm{C}\right)$. (d) SEM fractograph of (c). 
Table I. Densities and Porosities of As-Nitrided Samples and Such Samples Further Treated at Different Temperatures

\begin{tabular}{|c|c|c|c|c|c|}
\hline $\begin{array}{l}\text { Temperature } \\
{\left[\mathrm{K}\left({ }^{\circ} \mathrm{C}\right)\right]}\end{array}$ & $\begin{array}{l}\text { Liquid } \\
\text { Fraction } \\
\text { (Wt Pct) }\end{array}$ & $\begin{array}{c}\text { Bulk } \\
\text { Density } \\
\left(\mathrm{g} \mathrm{cm}^{-3}\right)\end{array}$ & $\begin{array}{c}\text { Total } \\
\text { Porosity } \\
\text { (Vol Pct) }\end{array}$ & $\begin{array}{c}\text { Open } \\
\text { Porosity } \\
\text { (Vol Pct) }\end{array}$ & $\begin{array}{c}\text { Open-Pore } \\
\text { Fraction (Pct) }\end{array}$ \\
\hline As-nitrided & 0 & $1.42 \pm 0.01$ & $49.2 \pm 0.5$ & $37.7 \pm 0.4$ & $76.6 \pm 1.5$ \\
\hline $893(620)$ & 5.6 & $1.42 \pm 0.01$ & $50.9 \pm 0.3$ & $35.8 \pm 0.9$ & $70.4 \pm 2.2$ \\
\hline $913(640)$ & 26.7 & $1.56 \pm 0.00$ & $44.2 \pm 0.0$ & $28.1 \pm 0.6$ & $63.5 \pm 1.5$ \\
\hline $923(650)$ & 76.4 & $1.53 \pm 0.04$ & $45.4 \pm 1.5$ & $13.6 \pm 3.0$ & $30.0 \pm 7.6$ \\
\hline $973(700)$ & 100 & $1.52 \pm 0.07$ & $45.7 \pm 2.7$ & $3.6 \pm 1.6$ & $7.8 \pm 4.0$ \\
\hline
\end{tabular}

thermally remove the nylon and form an AIN skeleton. Finally, the part was treated at $973 \mathrm{~K}\left(700^{\circ} \mathrm{C}\right)$ under vacuum for 2 hours to close the pores.

\section{RESULTS AND DISCUSSION}

\section{A. Open-Closed Pore Transformation}

During nitridation at $833 \mathrm{~K}\left(560{ }^{\circ} \mathrm{C}\right)$, particles of AA6061 in the AA6061-2Mg-1Sn mix react with nitrogen to form an AIN shell on each particle surface. ${ }^{[18-21]}$ These interconnected A1N shells form a skeleton imparting strength to the nitrided assembly, transforming the loose powder into a rigid but porous material. Figure 1(a) shows an optical micrograph of the nitrided structure, and Figure 1(b) is an SEM fractograph of the same structure. The space between the AlN shells forms an interconnected open-pore structure.

Figure 1(c) shows the attendant microstructure when the sample was further heated to $973 \mathrm{~K}\left(700{ }^{\circ} \mathrm{C}\right.$ ) (above the liquidus of AA6061) and held at temperature for 2 hours, followed by furnace cooling. A distinctly different microstructure is observed, with aluminum filling the interconnected channels outside the shells. As a result, the pores were transformed from largely open and interconnected to closed and isolated. Figure 1(d) shows the closed pores on the fracture surface of such a sample.

The bulk density, porosity, and open-pore fraction of samples before and after the open-closed pore transformation at $973 \mathrm{~K}\left(700{ }^{\circ} \mathrm{C}\right)$ are listed in Table I. While the bulk density increases slightly from 1.42 to $1.52 \mathrm{~g} \mathrm{~cm}^{-3}$, open porosity decreases from 37.7 pct in the untreated sample to $3.6 \mathrm{pct}$ in the sample treated at $973 \mathrm{~K}$ $\left(700{ }^{\circ} \mathrm{C}\right)$. As a result, the open-pore fraction decreases from 76.6 to 7.8 pct.

The difference in the open-pore fraction between the as-nitrided and treated samples is best demonstrated through the experiment shown in Figure 2. The beaker was filled with hydrofluoropolyether liquid $\mathrm{HCF}_{2} \mathrm{O}-\left(\mathrm{CF}_{2} \mathrm{O}\right)_{n}-\left(\mathrm{CF}_{2} \mathrm{CF}_{2} \mathrm{O}\right)_{m}-\mathrm{CF}_{2} \mathrm{H}$ (commercial name: H-Galden ZT 180 (Solvay Solexis, SpA, Milan, Italy), density $1.69 \mathrm{~g} \mathrm{~cm}^{-3}$ at $\left.298 \mathrm{~K}\left(25^{\circ} \mathrm{C}\right)\right)$. Although the bulk density of the as-nitrided sample $\left(1.42 \mathrm{~g} \mathrm{~cm}^{-3}\right)$ is less than that of the liquid, it sinks because the openpore structure permits liquid infiltration. In contrast, the sample treated at $973 \mathrm{~K}\left(700{ }^{\circ} \mathrm{C}\right)$, although having a bulk density $\left(1.52 \mathrm{~g} \mathrm{~cm}^{-3}\right)$ higher than that of the as-nitrided sample, floats on the liquid, demonstrating that its closed pore structure has effectively prevented liquid permeation.

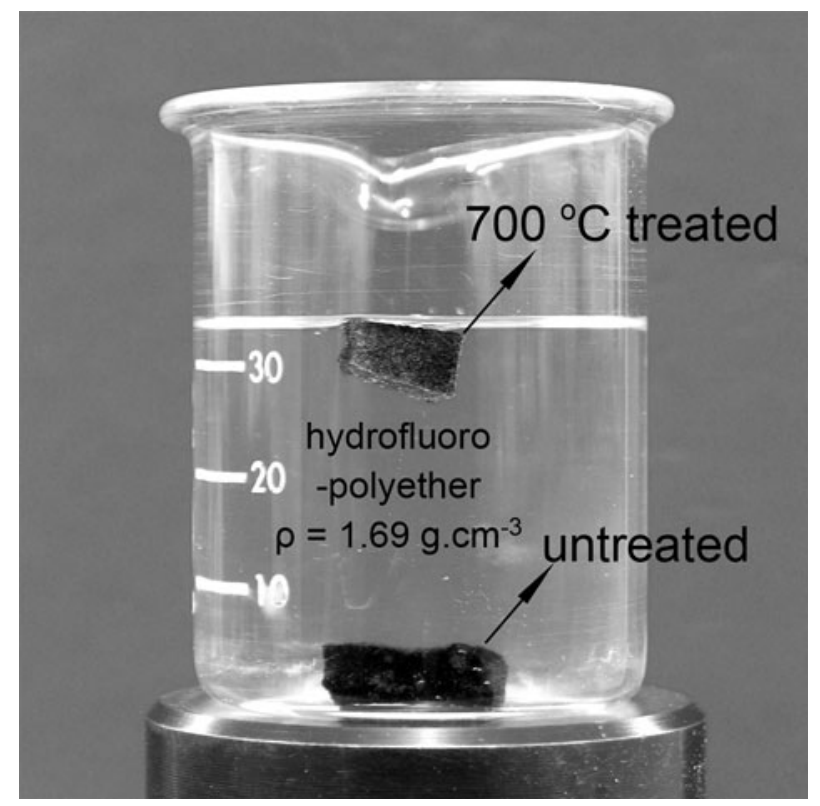

Fig. 2-Floating experiment in hydrofluoropolyether. The untreated sample sinks due to its open-pore structure, while the sample after the transformation treatment at $973 \mathrm{~K}\left(700{ }^{\circ} \mathrm{C}\right)$ floats due to its closed pore structure.

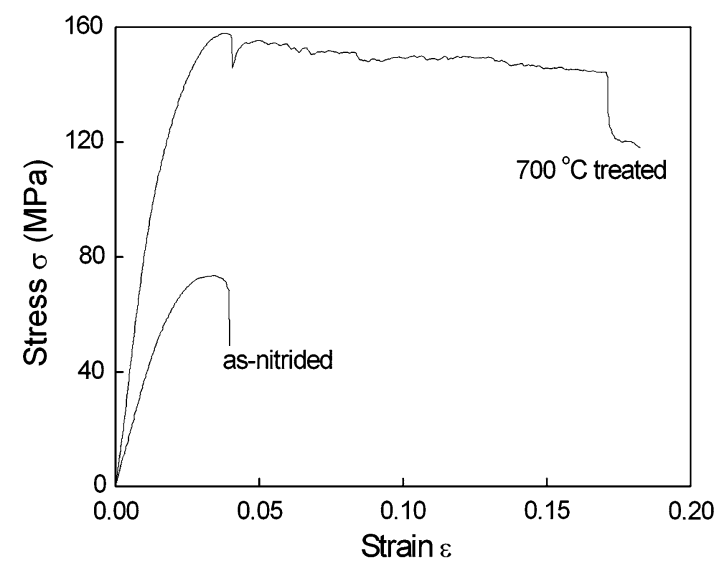

Fig. 3-Compression testing curves of samples before and after the open-closed pore transformation at $973 \mathrm{~K}\left(700{ }^{\circ} \mathrm{C}\right)$.

The difference in the pore structure is further reflected by the difference in the compressive properties shown in Figure 3, with detailed information summarized in Table II. In the as-nitrided sample, each AA6061 particle is enveloped by an AIN shell, which isolates the 
ductile AA6061 grains. The sample relies exclusively on the AlN skeleton to bear the compressive loading. After the transformation treatment at $973 \mathrm{~K}\left(700^{\circ} \mathrm{C}\right)$, the ductile AA6061 forms an interconnected structure, which bears the load with the AlN skeleton, imparting additional strength and ductility to the sample. As a result, the sample treated at $973 \mathrm{~K}\left(700{ }^{\circ} \mathrm{C}\right)$ exhibits an ultimate strength of $147 \mathrm{MPa}$ and a Young's modulus of $8.3 \mathrm{GPa}$, almost twice the properties of the untreated samples.

Table II. Mechanical Properties of Untreated Samples and Those Treated at $973 \mathrm{~K}\left(700{ }^{\circ} \mathrm{C}\right)$

\begin{tabular}{lccr}
\hline Samples & Yield Strength $(\mathrm{MPa})$ & Compressive Strength (MPa) & Young's Modulus (GPa) \\
\hline As-nitrided & $60 \pm 3$ & $80 \pm 6$ & $4.3 \pm 0.7$ \\
$973 \mathrm{~K}\left(700^{\circ} \mathrm{C}\right)$ treated & $106 \pm 4$ & $147 \pm 6$ & $8.3 \pm 0.6$ \\
\hline
\end{tabular}
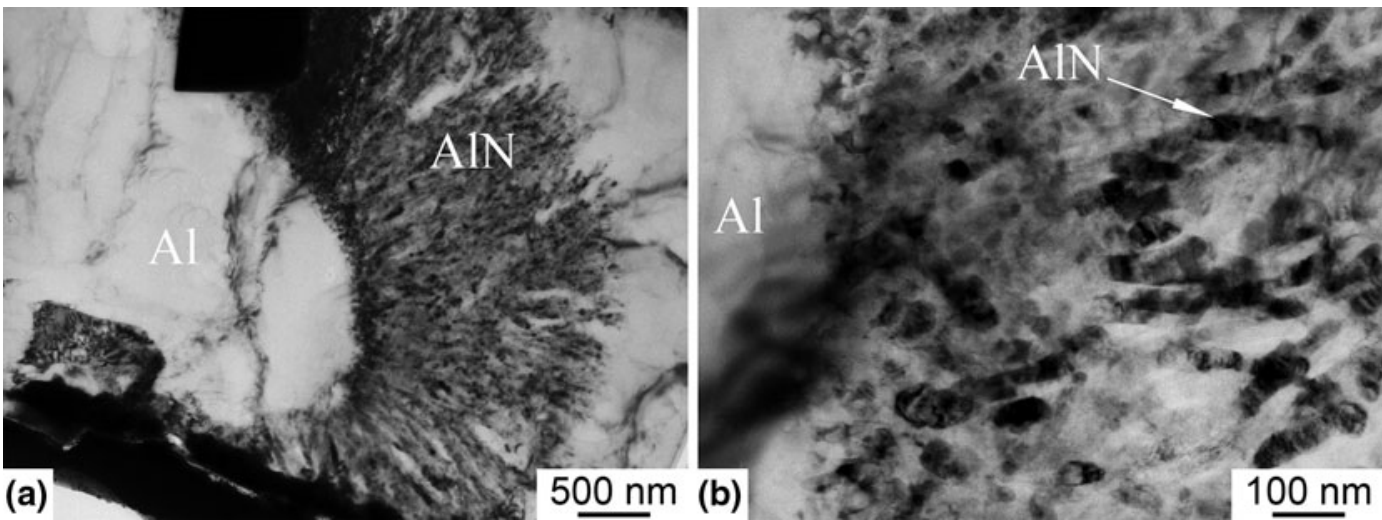

Fig. 4-TEM micrographs of the sample after the transformation at $973 \mathrm{~K}\left(700^{\circ} \mathrm{C}\right)$ showing the permeable AlN shell structure consisting of AIN whiskers growing from the surface of the prior AA6061 particle. $(b)$ Magnified view of $(a)$.
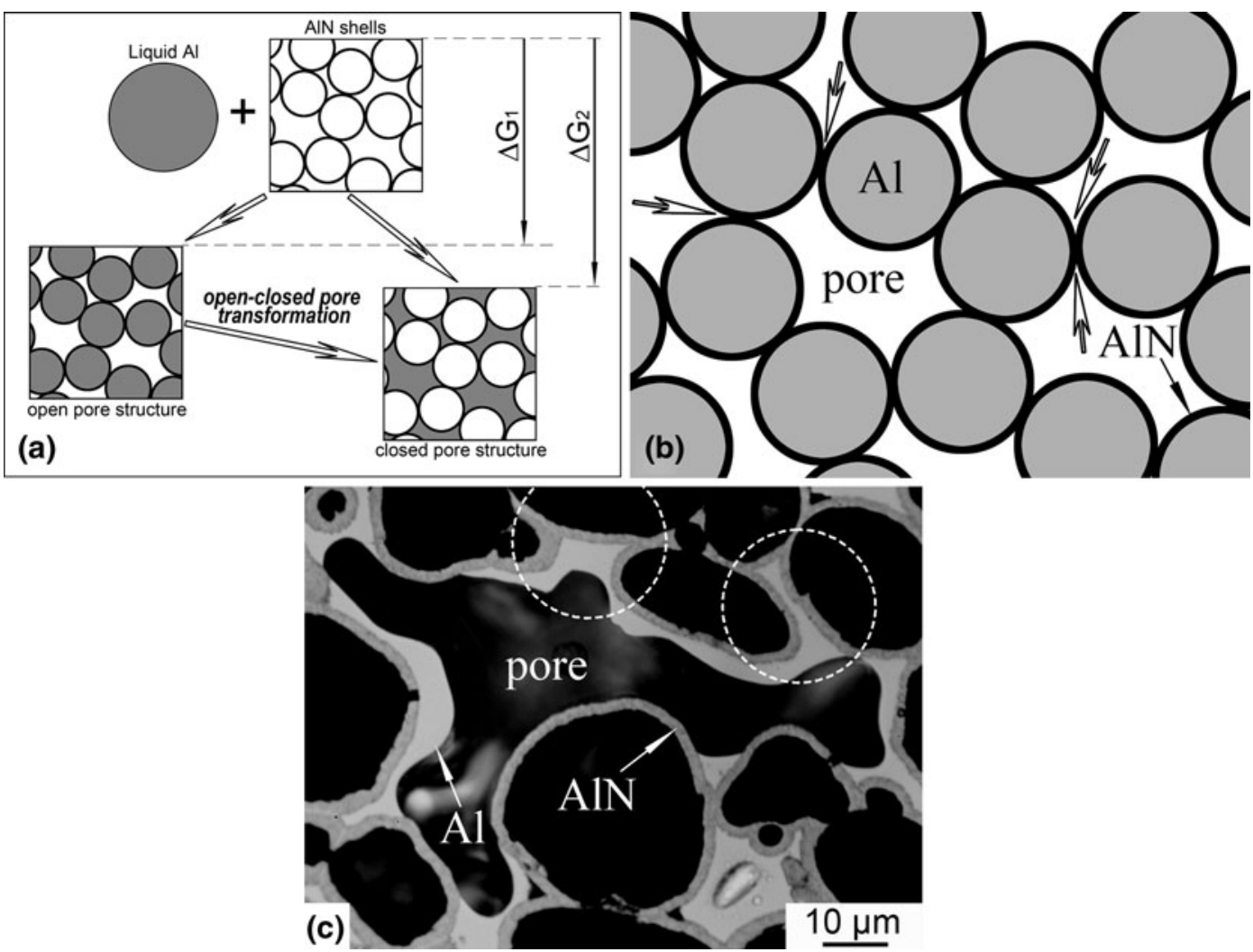

Fig. 5- (a) Schematic illustration of the thermodynamics of the open-closed pore transformation process. $(b)$ The space outside the AlN shells shows concave features of large curvature at shell junctions (labeled with open arrows), which make the porous structure thermodynamically unstable. (c) Optical micrograph of a sample after transformation at $973 \mathrm{~K}\left(700{ }^{\circ} \mathrm{C}\right)$; the concave junctions are filled preferentially. 


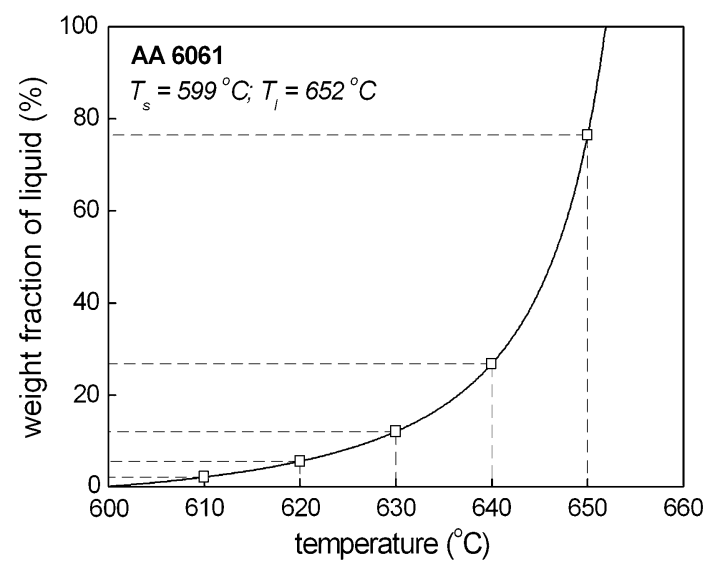

Fig. 6-THERMO-CALC predictions of liquid fraction in the semisolid region of AA6061.

\section{B. Mechanism of Open-Closed Pore Transformation}

Figures 4(a) and (b) show bright-field TEM images of the AlN shell formed in a sample treated at $973 \mathrm{~K}$ $\left(700{ }^{\circ} \mathrm{C}\right)$. The shell is $\sim 2-\mu \mathrm{m}$ thick and is composed of many discrete AlN whiskers growing from the surface of each AA6061 particle. The interstices between the AlN whiskers are filled with solidified aluminum at room temperature, ${ }^{[22]}$ which melts when heated above the liquidus. This permits the passage of molten aluminum through the AlN shell and the redistribution of the aluminum from inside the shells to the outside.

To understand the redistribution of molten AA6061, it is necessary to investigate the interfacial energy of the system. Figure 5(a) illustrates the interfacial energy change of the open-closed pore transformation. It has been shown previously that the wetting of AlN skeleton
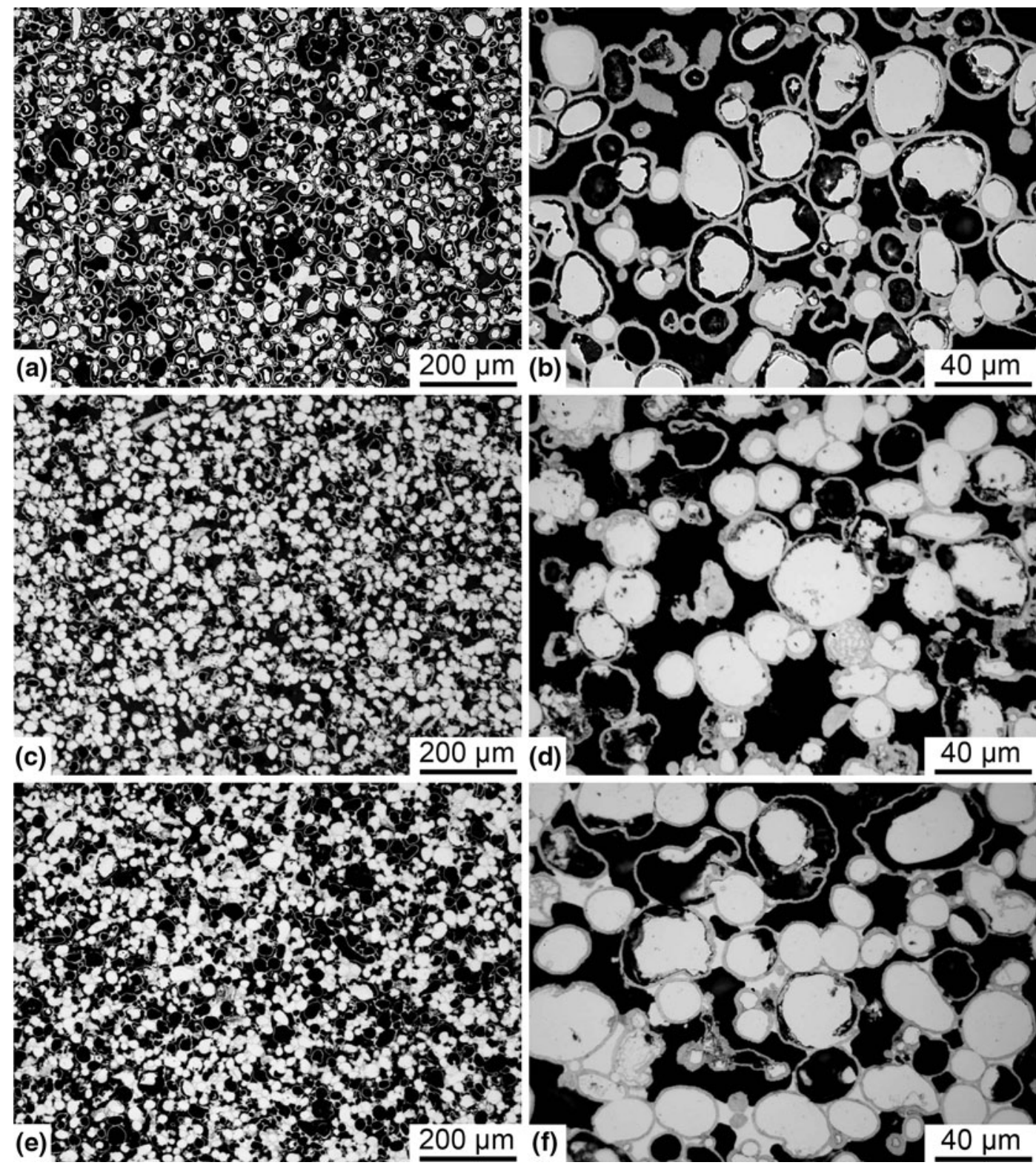

(b)
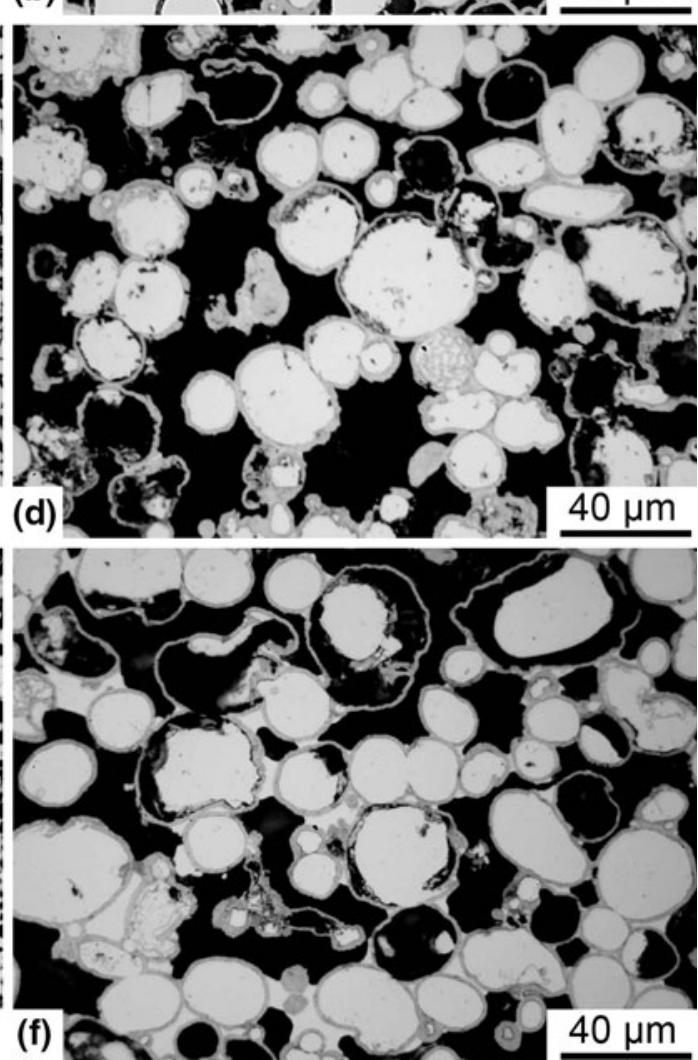

Fig. 7- (a) and (b) Optical micrographs of as-nitrided samples and samples treated at different temperatures for $2 \mathrm{~h}:(c)$ and $(d) 893 \mathrm{~K}\left(620{ }^{\circ} \mathrm{C}\right)$, $(e)$ and $(f), 913 \mathrm{~K}\left(640{ }^{\circ} \mathrm{C}\right),(g)$ and $(h) 923 \mathrm{~K}\left(650^{\circ} \mathrm{C}\right)$, and $(i)$ and $(j) 973 \mathrm{~K}\left(700{ }^{\circ} \mathrm{C}\right)$. 

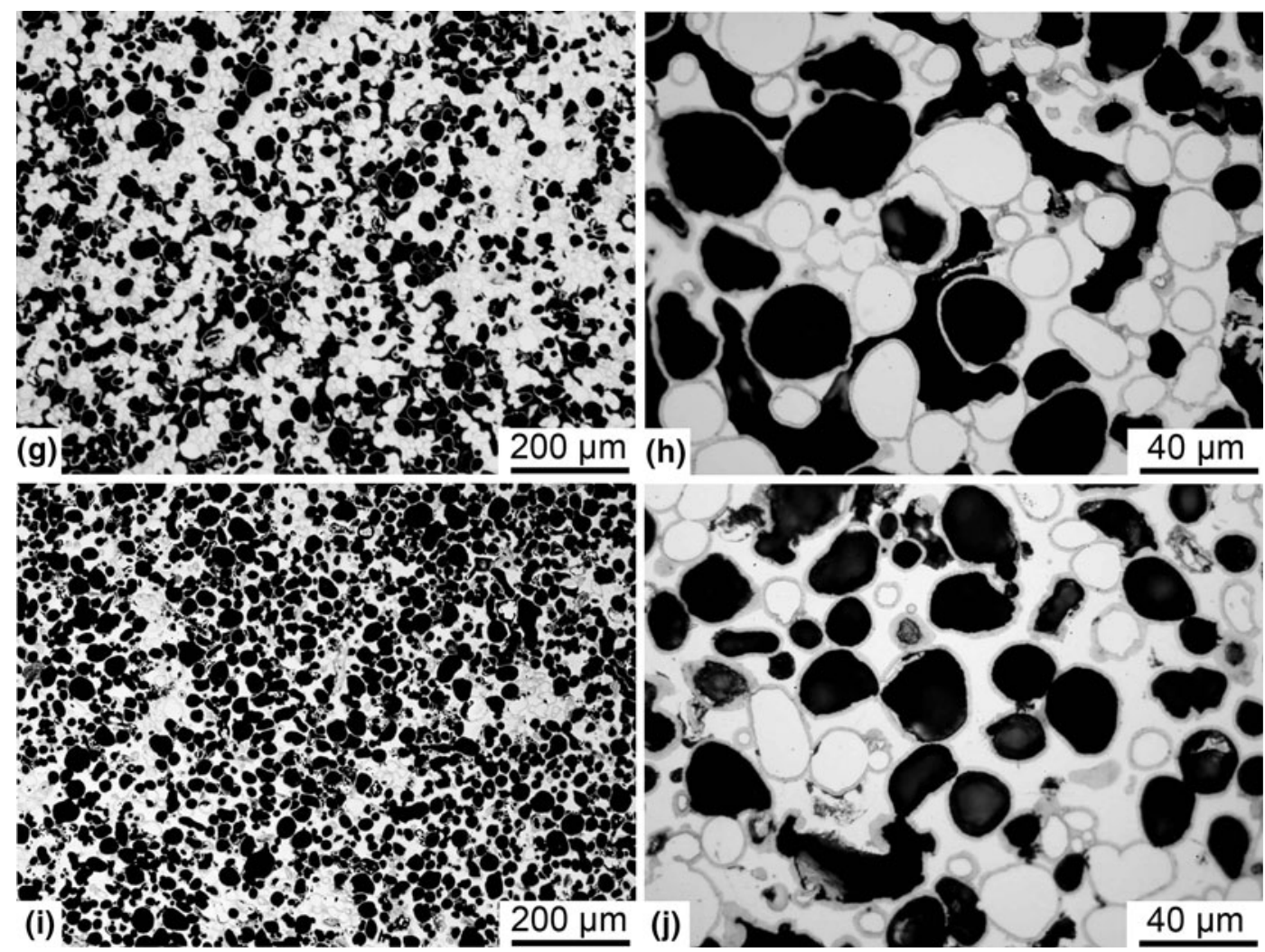

Fig. 7-Continued.

by molten AA6061 alloy under vaccum is sufficient for spontaneous infiltration. ${ }^{[18-20]}$ According to the Young's equation, this implies that the solid/liquid (AlN/ AA6061) surface tension $\gamma_{s l}$ is lower than the solid/gas (AlN/vacuum) surface tension $\gamma_{s g}$, namely,

$$
\gamma_{s l}<\gamma_{s g}
$$

Consequently, the overall interfacial energy of the system decreases when the open pores between the AlN shells are filled by molten AA6061 (Figure 5(a)). The energy change is greatly affected by the size and morphology of the pores. When a pore of radius $r$ is filled, the resulting change of the interfacial Gibbs free energy, $\Delta G$, is given by

$$
\Delta G=\left(\gamma_{s l}-\gamma_{s g}\right) \cdot A
$$

where $A$ is the surface area of the pore. For a given volume of infiltrant $(V)$, the ratio of $\Delta G$ to $V$ is

$$
\frac{\Delta G}{V}=\frac{\left(\gamma_{s l}-\gamma_{s g}\right) \cdot 4 \pi r^{2}}{4 \pi r^{3} / 3}=\frac{3 \cdot\left(\gamma_{s l}-\gamma_{s g}\right)}{r}
$$

Equation [7] suggests that filling of pores with the smallest radius by molten AA6061 will lead to the largest reduction in the Gibbs free energy. The pores with smallest radius therefore are expected to fill preferentially. For the same reason, portions with the smallest radii of curvature (or largest curvature) in nonspherical pores will be filled preferentially. This pore filling pattern was confirmed previously. ${ }^{[19,21]}$
Figure 5(b) schematically illustrates the microstructure of a porous aluminum structure prior to the openclosed pore transformation, with $\mathrm{Al}$ inside each AIN shell. There are concave regions outside the AlN shells where the radii of curvatures are infinitely small (labeled with open arrows in Figure 5(b)). This makes the system thermodynamically unstable. Upon melting, AA6061 will spontaneously migrate through the permeable AIN shells to fill these regions to minimize the overall Gibbs free energy of the system. In places where the AA6061 particles are closely packed so that the space outside the AlN shells is smaller than that inside, the infiltrant can completely fill the outside space. As a result, the open pores outside the AlN shells will be eliminated while closed pores will be created inside the AlN shells. In places where the AA6061 particles are loosely packed such that the space outside the AlN shells is greater than the inside (as seen in Figure 5(c)), only the concave regions (labeled with broken circles in Figure 5(c)) will be filled, leaving the rest of the outside space unfilled. Nevertheless, most open pores can be transformed into closed pores at an appropriate temperature.

The open-closed pore transformation occurs spontaneously, driven by the decrease in the overall interfacial energy of the system (Figure 5(a)). The phenomenon should not be limited to the Al-AlN system. Rather, we expect that similar open-closed cell transformations may be realized in other systems subject to the following conditions. First, the system has a core-shell structure 
where the shell has a higher melting point than the core and is well wetted by the molten core material. Second, the shell is permeable and permits the passage of the molten core material. Last, the space outside the shells has substructures whose radii of curvatures are smaller than that of the pores inside the shells, ensuring spontaneous redistribution of the molten core material from inside to outside the shell.

\section{Porous Al with Controllable Open-Pore Fraction}

The open-closed pore transformation provides a means to control the open-pore fraction of porous materials. AA6061 has a semisolid region (liquidus = $925 \mathrm{~K}\left(652^{\circ} \mathrm{C}\right)$, solidus $=872 \mathrm{~K}\left(599^{\circ} \mathrm{C}\right)$; Figure 6$)$ through which the liquid fraction can be readily manipulated. When a nitrided AA6061 sample is treated to and held at $893 \mathrm{~K}, 913 \mathrm{~K}$, and $923 \mathrm{~K}\left(620{ }^{\circ} \mathrm{C}, 640{ }^{\circ} \mathrm{C}\right.$, and $650{ }^{\circ} \mathrm{C}$ ), the corresponding equilibrium liquid fractions are 5.6, 26.7, and 76.4 (all in wt pct), respectively. The liquid will penetrate the AlN shell and fill the outside space, while the solid will remain inside the shell. As a result, the openclosed pore transformation can be controlled quantitatively, resulting in different open-pore fractions.

Figure 7 shows typical optical micrographs of untreated samples and those treated at various

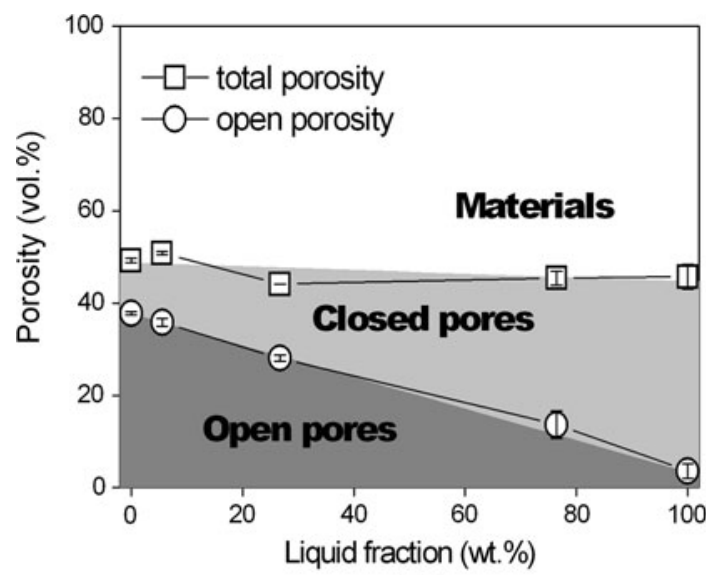

(a)

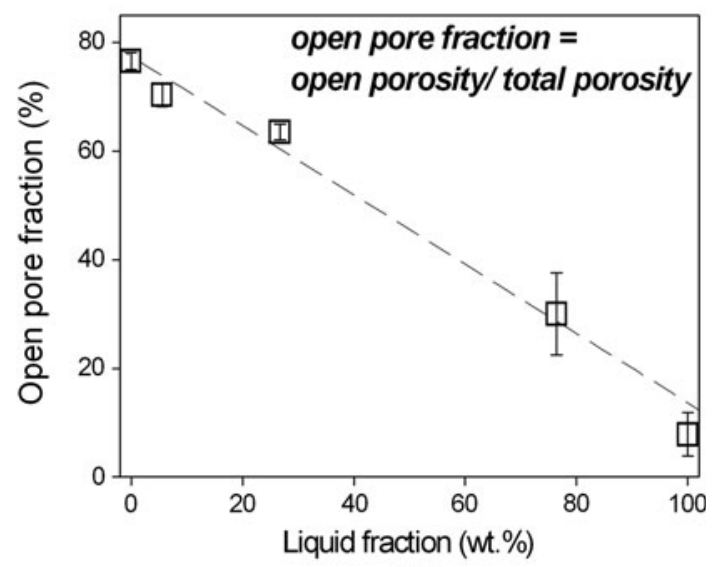

(b)

Fig. 8-(a) Total porosity and open porosity and (b) open-pore fraction as a function of liquid fraction. temperatures depicting different stages of an open-closed pore transformation process. The degree of transformation increases with increasing temperature due to increased liquid formation. The liquid fraction, density, and porosity of samples treated at different temperatures are summarized in Table I. The results are plotted in Figure 8(a). Although the total porosity varies little with increasing liquid fraction, the open porosity decreases linearly with increasing liquid fraction. Accordingly, the open-pore fraction, defined as the ratio of open porosity to total porosity, drops from 76.6 to 7.8 pet (Figure $8(\mathrm{~b})$ ).

\section{Application of Open-Closed Pore Transformation to Net Shape Fabrication}

The open-closed pore transformation can be readily transplanted to rapid prototyping or powder injection molding to fabricate porous aluminum parts with a desired shape and controllable open-pore fraction. Figure 9 shows such an example, which has thin walls and a hollow structure. The green compact was prepared through selective laser sintering of an AA6061-2 pet Mg-1 pet Sn-3 pet Nylon mix. It was subjected to 12 hours nitridation at $833 \mathrm{~K}\left(560^{\circ} \mathrm{C}\right)$ and an open-closed pore transformation at $973 \mathrm{~K}\left(700{ }^{\circ} \mathrm{C}\right)$ under vacuum.

\section{CONCLUSIONS}

A novel open-closed pore transformation was identified and realized for the fabrication of porous aluminum alloys with controllable pore structure. A powder

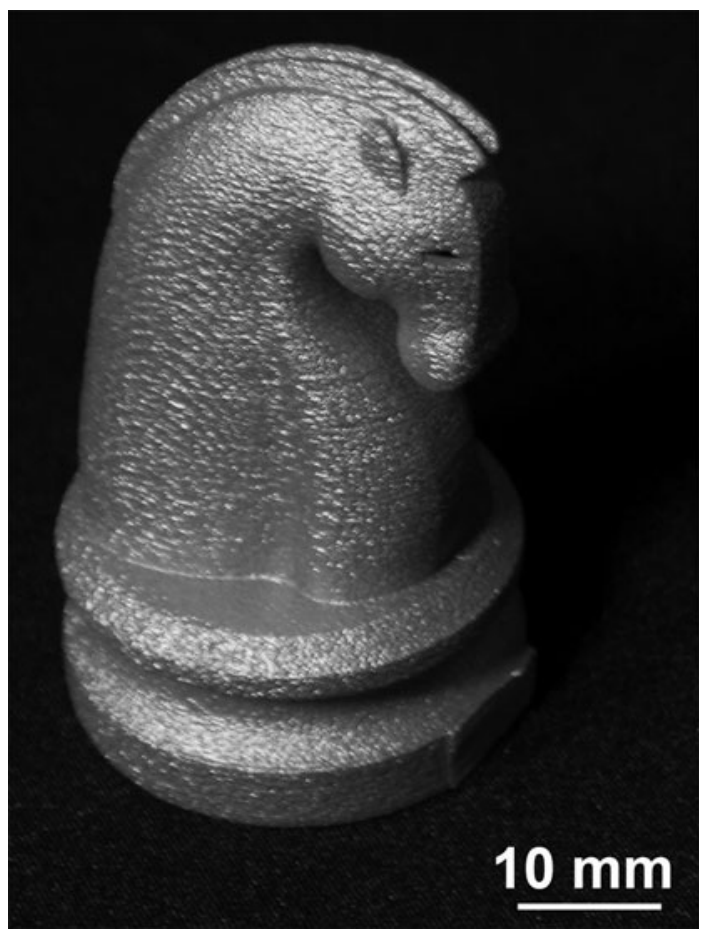

Fig. 9-A closed-pore aluminum part made by selective laser sintering, nitridation at $833 \mathrm{~K}\left(560^{\circ} \mathrm{C}\right)$, and an open-closed pore transformation treatment at $973 \mathrm{~K}\left(700^{\circ} \mathrm{C}\right)$. 
mixture of AA6061-2 pet Mg-1 pet $\mathrm{Sn}$ is first nitrided in high-purity nitrogen at $833 \mathrm{~K}\left(560{ }^{\circ} \mathrm{C}\right)$ for 12 hours. This creates a permeable AIN shell on each AA6061 particle. As a result, the spaces outside the AlN shells form a percolating structure transforming the mix into an open-pore material. The AlN shells are interconnected, imparting strength to the open-pore material. When the porous structure is heated above the liquidus of AA6061 under vacuum, the molten core (AA6061) in each AlN shell flows through the permeable shell and fills the open pores outside, leaving a closed pore inside. The open-closed pore transformation is driven by a reduction in the interfacial energy of the system. Based on this finding, porous AA6061 with different open-pore fractions was fabricated by heating open-pore AA6061 in the semisolid region, where the liquid fraction depends on temperature. Consequently, the solid remains inside the AIN shell, while the liquid migrates to fill the open pores.

\section{ACKNOWLEDGMENT}

The work was funded by the Australian Research Council.

\section{REFERENCES}

1. K. Ishzaki, S. Komarneni, and M. Nanko: Porous Materials: Process Technology and Applications, Kluwer Academic, London, 1998.
2. S.J. Hollister: Nat. Mater., 2005, vol. 4, pp. 518-24.

3. H. Hayashi, A.P. Cote, H. Furukawa, M. O'Keeffe, and O.M. Yaghi: Nat. Mater., 2007, vol. 6, pp. 501-06.

4. J. Banhart: Prog. Mater. Sci., 2001, vol. 46, pp. 559-632.

5. G.J. Davies and S. Zhen: J. Mater. Sci., 1983, vol. 18, pp. 18991902.

6. H. Fan, C. Hartshorn, T. Buchheit, D. Tallant, R. Assink, R. Simpson, D.J. Kissel, D.J. Lacks, S. Torquato, and C.J. Brinker: Nat. Mater., 2007, vol. 6, pp. 418-23.

7. F. Diologent, E. Combaz, V. Laporte, R. Goodall, L. Weber, F. Duc, and A. Mortensen: Scripta Mater., 2009, vol. 61, pp. 351-54.

8. B. Jiang, N.Q. Zhao, C.S. Shi, and J.J. Li: Scripta Mater., 2005, vol. 53, pp. 781-85

9. Y. Conde, J.F. Despois, R. Goodall, A. Marmottant, L. Salvo, C.S. Marchi, and A. Mortensen: Adv. Eng. Mater., 2006, vol. 8, pp. 795-803.

10. J. Banhart: JOM, 2000, vol. 52, pp. 22-27.

11. J. Banhart and H.W. Seelinger: Adv. Eng. Mater., 2008, vol. 10, pp. 793-802.

12. J. Banhart: Adv. Eng. Mater., 2006, vol. 8, pp. 781-94.

13. J.F. Despoise and A. Mortensen: Acta Mater., 2005, vol. 53, pp. 1381-88.

14. A. Bansiddhi and D.C. Dunand: Acta Biomater., 2009, vol. 4, pp. 1996-2007.

15. M.E. Davis: Nature, 2002, vol. 417, pp. 813-21.

16. I. Akartuna, A.R. Studart, E. Tervoort, and L.J. Gauckler: $A d v$. Mater., 2008, vol. 20, pp. 4714-18.

17. X.S. Zhao, F. Su, Q. Yan, W. Guo, X.Y. Bao, L. Lv, and Z. Zhou: J. Mater. Chem., 2006, vol. 16, pp. 637-48.

18. T.B. Sercombe and G.B. Schaffer: Science, 2003, vol. 301, pp. 1225-27.

19. P. Yu and G.B. Schaffer: Acta Mater., 2009, vol. 57, pp. 163-70.

20. T.B. Sercombe and G.B. Schaffer: Acta Mater., 2004, vol. 52, pp. 3019-25.

21. P. Yu, M. Qian, L. Li, and G.B. Schaffer: Acta Mater., 2010, vol. 58, pp. 3790-97.

22. D. Kent, M. Qian, and G.B. Schaffer: Powder Metall., 2010, vol. 53, pp. 118-24. 